\title{
SOME ASPECTS OF FUTURE ENERGY GENERATION IN USING OF SOLAR POWER SATELLITES
}

\section{MUNCHO J. MBUNWE1, UDOCHUKWU B. AKURU1, HILARY U. EZEA², OGBONNAYA I. $\mathrm{OKORO}^{3}$, M. AYAZ AHMAD ${ }^{4, *}$}

${ }^{1}$ Department of Electrical Engineering, University of Nigeria, Nsukka, Nsukka 410001, Nigeria ${ }^{2}$ Department of Electrical and Electronics Engineering, Federal University, Oye-Ekiti, Ekiti, Nigeria

${ }^{3}$ Department of Electrical and Electronic Engineering, Michael Okpara University of Agriculture, Umudike, Umuahia 440001, Nigeria

${ }_{4}^{4}$ Physics Department, Faculty of Science, P.O. Box 741, University of Tabuk, 71491, Saudi Arabia *Corresponding author: mayaz.alig@gmail.com

\begin{abstract}
Energy, which is required to run space satellites, is as old as space technology itself. The location of these satellites has made it more applicable for unconventional means of energy generation to run them. The Sun being the universal and greatest source of all forms of energy, as well as the closest energy source to space satellites, has been so appropriately trapped using solar cells. Solar power satellites are designed to capture solar energy and transmit that energy to receiving stations using wireless power transmission mechanism. This paper is written to rehearse the immediate and associated usefulness of solar energy trapped from space as an alternative for electricity generation for the future; it is also an attempt to appraise the prospects of this scientific conviviality.
\end{abstract}

Received 2019-05-01; accepted 2019-11-18; published 2020-01-02.

2010 Mathematics Subject Classification. 82B31.

Key words and phrases. solar energy; solar cells; SPS; sun; wireless power transmission.

(C)2020 Authors retain the copyrights of their papers, and all open access articles are distributed under the terms of the Creative Commons Attribution License. 


\section{INTRODUCTION}

Space satellites are generally regarded as spacecraft that receive signals and send them back to earth. However, they are extremely complex and expensive because they have to work and survive in space for specified time periods, usually up to 15 years. To make this possible, a satellite has to produce its own power by generating electricity from sunlight falling on photovoltaic cells or solar panels. Batteries are used to store the energy, so that the satellite can continue to work when the Sun is eclipsed or far away.

Because space is not a friendly environment, space satellites have to survive temperature variations of more than $200^{\circ} \mathrm{C}$ in a situation described similarly to someone standing in front of a fireplace with a blazing fire while an air conditioner pumps freezing air onto his back. Outside the protection of the earth's atmosphere, the level of radiation (UV, X-rays, gamma-rays and all sorts of energetic particles) is much higher and more destructive than on the ground. Before they can even begin to operate in space, satellites have to survive the bone-shaking launch. Then the solar panels have to be opened and antennas, which are often stowed to take less space in the launcher, deploys before the satellite enters its operational orbit. This is responsible for the high amount of time and the great number of professionals needed in designing, building and checking for the correct functioning of a satellite.

Electrical power delivery to earth using space power satellites (SPS) has a lot of similarities with space satellite technology. Peter Glaser, an American aerospace engineer, first proposed SPS in the late 60s [1], [2]. During the energy crises in the 70s, the US government took a hard look at them. The studies generated by this inquiry essentially reported that SPS were technologically possible but their cost and launch requirements were not. Fifteen years later NASA conducted a study to determine if anything had changed [3]. The new study concluded that costs were still high but they were not as high as originally predicted and that there were no technological showstoppers. At present, utility companies and governments are taking a closer look at SPS [4], [5]. Not only are they looking at them as sources of power on earth but also, as sources of power for satellites to reduce their size and launch costs [6].

SPS systems collect solar energy in space and transmit it via a microwave energy beam to an earth-based rectenna which converts the beam into electricity for use on earth, essentially defining the three stages of its operation (Fig. 1). SPS is thought to have several advantages over other forms of alternative energy, particularly over terrestrial implementation of solar power. 
For instance, power supply system based almost entirely on renewable energy source will have to deal with intrinsic variability of the resources [7]. Nevertheless, SPS is not affected by weather, seasons, or by the earth's atmosphere, which can otherwise act as a filter. Consequently, there is bound to be more intense exposure to sunlight not hindered by weather; hence no need for expensive storage which would have been of use during periods of low supply. Besides, it is harmless to the environment, and with less political interference, since it is environmental friendly, as there is no $\mathrm{CO}_{2}$ problem associated with it. Although, there have been contrary views that it is too early to implement this technology because of its huge investment requirement, safety concerns and an infantile technology, among others [8], [9]. As a result, this paper is another attempt at highlighting the feasibility and inevitability of the SPS technology for future electricity supply.

This paper has been organized as follows. Section 2 is used to highlight the need for future energy sources. Section 3 is used to briefly describe the SPS technology as well as their challenges. Section 4 is used to provide the state-of-the-art technology, while Section 5 is used to give a conclusion. Further, energy and power as used in this paper mean the same thing. Similarly, solar power satellite (SPS), space-based solar power (SBSP) or space solar power (SSP) as used correspondingly within this paper is without prejudice.

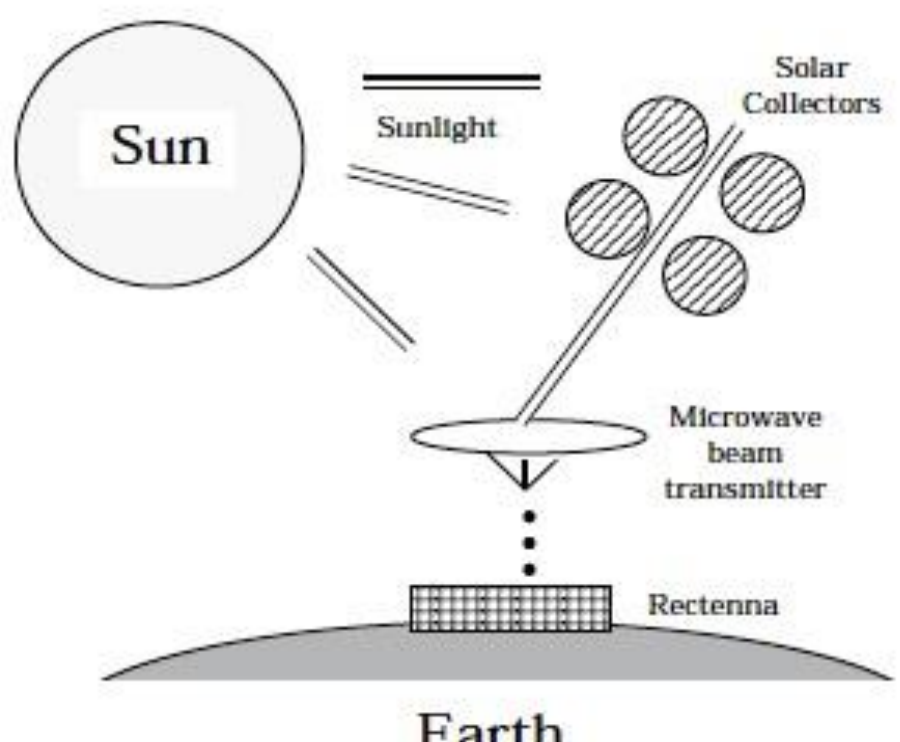

Fig. 1. Operational diagram of an SPS system 


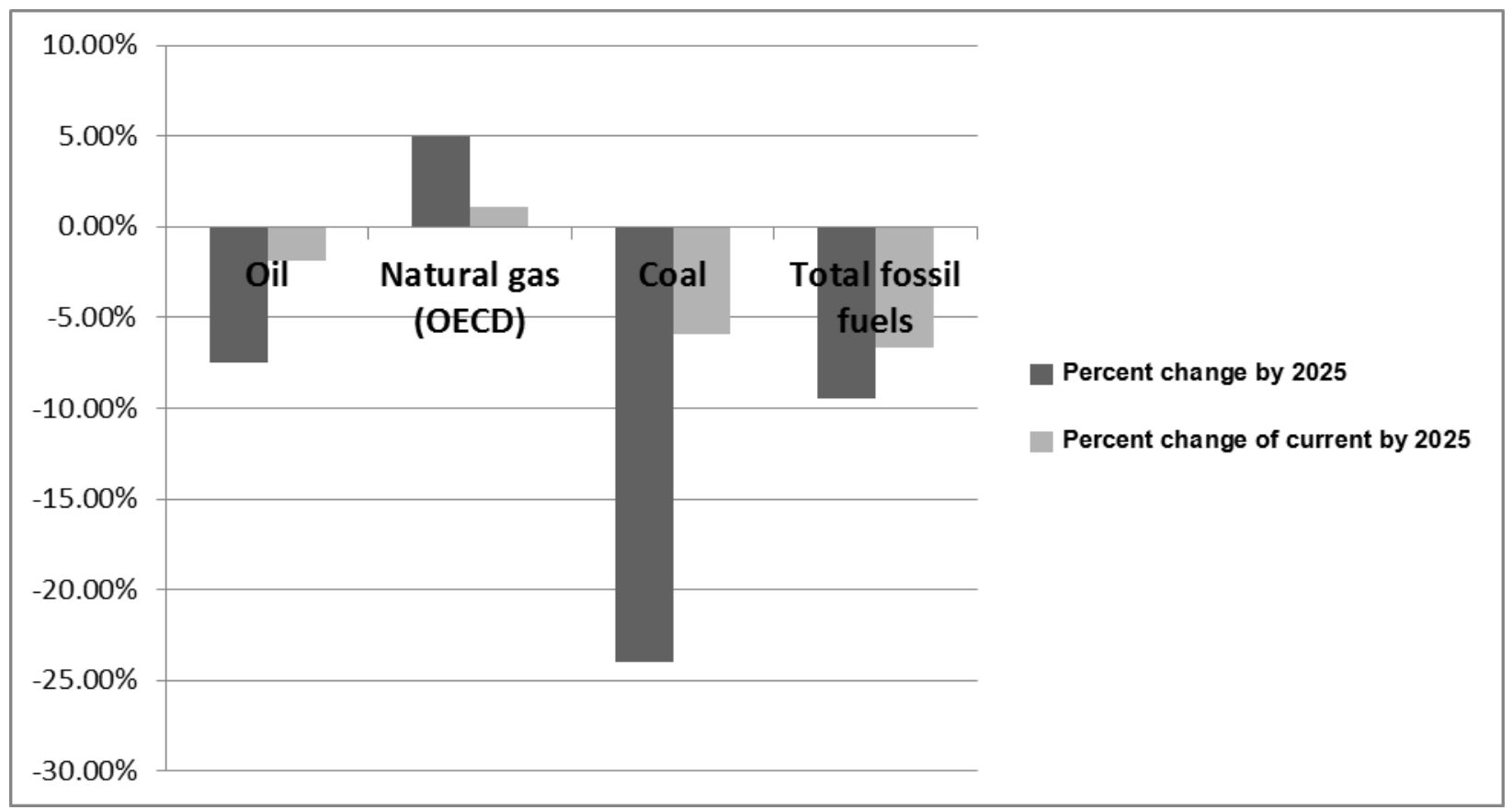

Fig. 2. Proposed change in supplies for fossil fuels

\section{THE NEED FOR FUtURE ENERGy SOURCES}

Currently, the world relies on fossil fuels to generate electrical power. The reality of a projected but certain fall of the world's oil reserve is confirmed in studies, e.g., [10]. Coal, a major source of energy supply is faced with a similar threat. Fig. 2 is meant to show the rate at which these energy sources are expected to decline in the coming years [11]. It is understandable that as the world population increases, the natural resources to produce energy decreases, and alternative methods to produce sustainable, environmentally friendly, and cost effective energy are required (Table 1). Meantime, fossil fuels are not only depleting, but altering local environment and the world climate [12]. In the same vein, all three factors petroleum peaking and declining, growing concerns of fuel-derived GHGs, and growing global demand for energy - were supported as the driving force for recent advancements in SPS technology [13].

Unlike nuclear energy which is equally clean and abundant but very risky, there is no doubt that renewable energy sources give a huge prospect for future energy sources because of its large reservoir and lowering cost of energy, even as it remains the world's fastest-growing source of electric power in the midst of ever increasing demand by end users [14]. In an era when new energy options are urgently needed, space solar power is an inexhaustible solution - 
SPS scores an edge over the ground-based (PV) solar power in three notable areas: increased availability, easy accessibility, higher efficiency [15] and the technologies to make it happen is now at an advanced stage [13].

In a paper, China Academy of Space Technology (CAST) grouped into three the major advantages of SPS to China's energy development as sustainable development, disaster prevention and mitigation, and retaining and cultivating talent [16]. Stating the several advantages to SPS, it was reported in ref. [17] that solar radiation can be more efficiently collected in space, where it is roughly three times stronger than on the surface of the earth and it can be collected 24 hours per day (since there are no clouds or night in high earth orbit). Thus, ensuring SPS does not use up valuable surface area on the earth by beaming to areas with the highest demand at any particular time. At the same time, current space missions are narrowly constrained by a lack of energy for launch and use in space. Missions that are more ambitious will never be realized without new, reliable, and less-expensive sources of energy [18]. Other benefits such as clean and safe energy source, limitless reserves and employment/investment opportunities make SPS the future energy system to beat. However, like every new technology, the next section is used to highlight some major concerns being raised against space-based solar power technology.

\section{TECHNOLOGY DEVELOPMENT AND CHALLENGES OF SPS}

Space-based solar power is a system for the collection of solar power in space for use on earth. SPS differs from the usual method of solar energy collection in that the solar panels used to collect the energy would reside on a satellite in orbit, rather than on earth's surface. In space, collection of the Sun's energy is unaffected by the day/night cycle, weather, seasons, or the filtering effect of earth's atmospheric gases. The average solar energy per unit area in space, i.e., vicinity of the Earth is $1366 \mathrm{~W} / \mathrm{m}^{2}$ as compared to less than an average of $250 \mathrm{~W} / \mathrm{m}^{2}$ obtainable on the surface of the earth. This drastic reduction in energy being as a result of atmospheric absorption and scattering, seasonal variations and weather [19]. 
TABLE 1. EXPECTED GROWTH RATE OF SUPPLy AND DEMAND OF ENERGY SOURCES [20]

\begin{tabular}{|c|c|c|c|}
\hline $\begin{array}{c}\text { Average projected } \\
\text { energy demand } \\
\text { growth }\end{array}$ & $\begin{array}{c}\text { Absolute change (as } \\
\text { percent of current } \\
\text { supply) by 2025 }\end{array}$ & $\begin{array}{c}\text { Necessary growth in } \\
\text { renewables + nuclear (percent } \\
\text { of current supply) by 2025 }\end{array}$ & $\begin{array}{c}\text { Necessary annual } \\
\text { growth in renewables } \\
\text { + nuclear }\end{array}$ \\
\hline $1 \%$ & $15 \%$ & $\mathbf{2 2} \%$ & $\mathbf{9 . 3 \%}$ \\
\hline $2 \%$ & $32 \%$ & $39 \%$ & $\mathbf{1 2 \%}$ \\
\hline $3 \%$ & $51 \%$ & $58 \%$ & $\mathbf{1 5 . 6 \%}$ \\
\hline $4 \%$ & $73 \%$ & $\mathbf{8 0} \%$ & $\mathbf{1 8 . 5} \%$ \\
\hline $5 \%$ & $98 \%$ & $\mathbf{1 0 5} \%$ & $\mathbf{2 0} \%$ \\
\hline
\end{tabular}

A. Overview of SPS Technology

Space based solar power is comprised of two major technologies which have been studied in some form since the 1980s [21], these are: architecture of the satellite and receiver module; and, the means to beam energy back to earth. Both possess challenges, with that of transmission technology being direr. To this, wireless power transmission has been identified as key to the development of SPS [22]. These two main technologies are further processed as:

1) Means of collecting solar power in space: Solar power collection in space can be achieved using planar photovoltaic cells or thermal turbines which convert the solar energy into dc electricity. [15]. The energy collector could be a single crystal silicon which receives direct sunlight and is readily available. However, silicon cells are vulnerable to radiation. The collector could as well be gallium arsenide photovoltaic cells which exhibit a level of resistance to both thermal and radiation degradation but is not readily available.

2) Means of transmitting power to earth: Due to long distances involved, wired transmission is impractical. Consequently, wireless power transmission is adopted. Usually, lower radio frequency transmission in the microwave spectrum $(2.45 \mathrm{GHz})$ or high frequencies within the optical and infrared range are required.

3) Means of receiving power on earth: The means of receiving the transmitted power depends on the transmission mode adopted during the transmission phase [17]. A rectenna (microwave-to-dc converter), which consists of a rectifying circuit and a receiving antenna most suitable for radio frequencies [23], while an array of photovoltaic cells are used for visible and infrared frequency ranges.

The SPS concept is very involved, and several integrated studies have been undertaken over the years to design produce an optimum template for its operation [6], [13], [19], [24]. The good 
news is that the basic physics of solar power satellites was resolved in the 1960s and 1970s, while the challenges over the years are, basically, engineering and economics [18]. The basic description of SPS, earlier shown in Fig. 1, can be adapted to two different architectures [19]:

1) GEO-based Solar Power Architecture: The satellite can be placed within the Geostationary orbit (GEO), medium-earth orbit (MEO) or low-earth orbit (LEO). In GEO, the satellite appears to be stationary because the speed of Earth's rotation corresponds to the orbital period of the satellite round the earth. Then due to its position, less than $1 \%$ of its total time is spent in shadow. If the satellite is placed in the LEO, this minimizes the range and brings about reduction in size and weight of the transmitting antenna. However, satellites in LEO have a reduced productivity owing to the fact that much of their time is spent in shadow as they orbit the earth.

2) Lunar Solar Power Architecture: Here, power collector and beam forming equipment are mounted on the moon surface. This architecture, however, is affected by the 14-day lunar night and as such, constant power is not ordinarily provided.

In general, three principal GEO-based SPS concepts (Fig. 3) which have been identified and characterized for technical and commercial applications are [13]:

1) Microwave Wireless Power Transmission (WPT)/Classic Power Management Architecture, involving large discrete structures (e.g., solar array, transmitter, etc.) assembled by a separate facility in space; this concept involves sun-pointed solar energy collection system, a wireless power transmission system which makes use for microwave radio frequency, and ground based rectennas which receive the transmitted power.

2) Modular Electric/Diode Array Laser WPT/Sandwich Power Management Architecture, involving self-assembling solar power-laser-thermal modules of intermediate scale; this can either be electric-laser or solar-pumped laser. The wireless power transmission here involves laser beam generation at the near visible part of the spectrum

3) Modular Microwave WPT/Sandwich Power Management Architecture, involving a large number of very small solar power-microwave-thermal modules that would robotically assemble in orbit. This is a highly modularized architecture which involves light-redirection based energy distribution approach and depends on an integration of 
solar generation, power management and distribution, as well as wireless power transmission subsystems on individual modules

So far, the highly modular microwave WPT sandwich SPS appears to be the more suitable, offering clear advantages particularly for large-scale commercial base-load power, with fabrication and prototype testing recently performed [25].

The generic functional architecture which can be used to describe any of the SPS concepts is as shown in Fig. 3, where other systems integral to the SPS concepts have been identified such as [12], [15]: 1) earth-to-orbit (ETO) transportation; 2) affordable in-space transportation; 3) space assembly, maintenance and servicing; and, 4) ground energy and interface systems; as well as, 5) in-space resources and manufacturing. It is believed that all of these technologies are reasonably near-term and have multiple attractive approaches. However, a great deal of work is needed to bring them to practical fruition.

\section{B. Challenges associated with SPS}

Key areas of concern in the SPS concept are in terms of emerging technology, international policy and regulations, health and safety, terrorism, as well as high costs. The aspect of terrorism comes in since high power microwave source with high gain antenna is usually employed in delivering intense burst of energy which can be used as a weapon [26]. The other problems associated with SPS find their roots among any of these main areas. For instance, considering how to transmit the energy from the collection point in space to the place where the energy would be used on earth, technology, cost and health factors become critical.

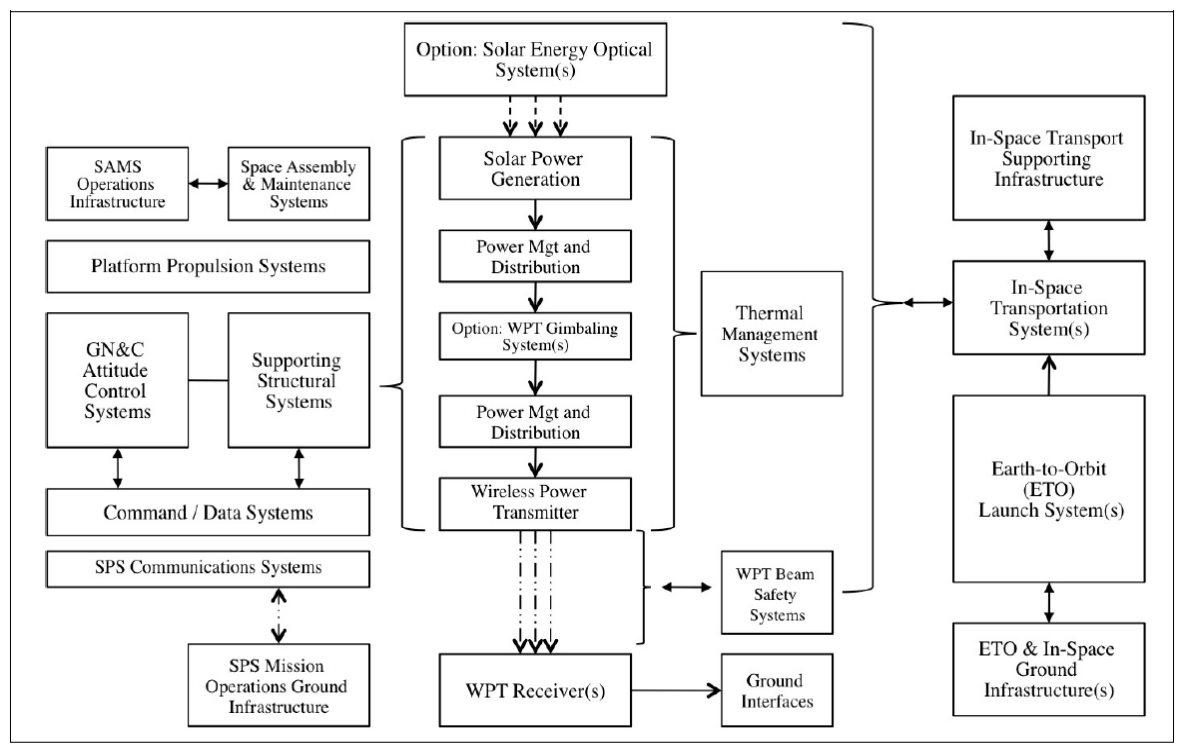

Fig. 3. Generic SPS functional architecture 

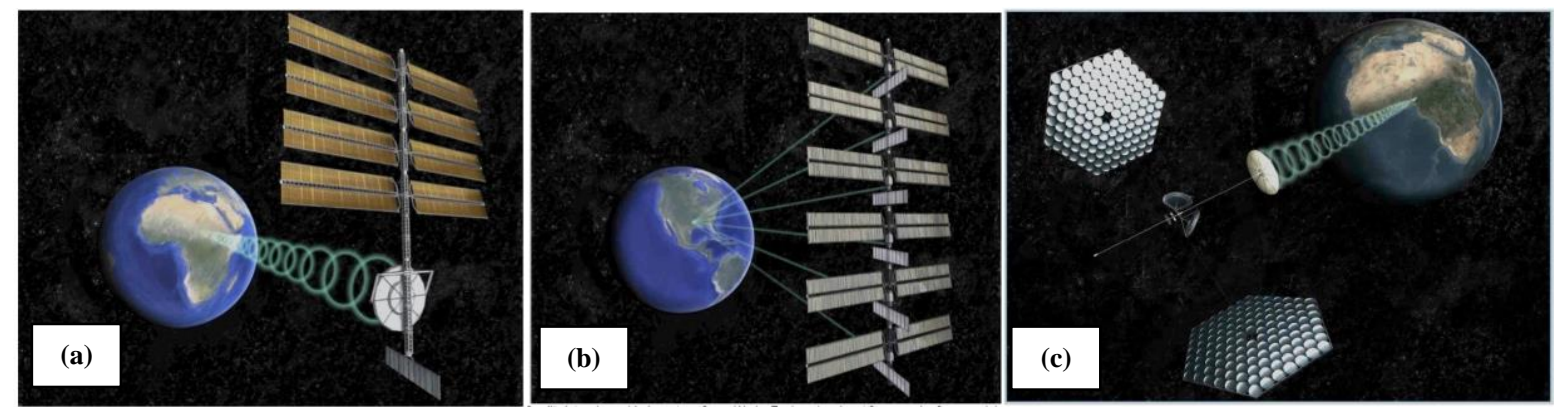

Fig. 4. Conceptualized GEO-based SPS: (a): Microwave Classic (b): Modular Electric Laser (c): Modular Sandwich Microwave Generic SPS functional architecture

The greatest barrier to the development of SPS has been identified as its high launch costs. As a result, a major spacecraft development project can cost many tens, if not hundreds, of millions of dollars, and over a lengthy period of time [27]. Such technical challenges greatly influence the economic feasibility of SPS. Yet, there are other myths bothering on safety for man, animals, high interference, space materials and orbit, machines and the environment [10].

However, in an attempt to delineate the advantages of SPS, it is implied that most of the observed challenges can be abated when the promise of bulk clean energy source of future growing energy demand, high transmission and conversion efficiency, ease of transmission, and non-hazardous radiation are factored [28].

\section{RECENT DEVELOPMENTS IN SPS TECHNOLOGY}

In recent times, more world governments have concentrated time and money to study and develop the SPS technology. Intense efforts, spanning a 40 years period, have been made in the US, Canada and Europe [28]. China and India both started recent activities, while Japan has been undertaking steady technological strides in harnessing the technology up to developmental stage. In the wake of the disaster at the Fukushima Daiichi nuclear power plant, Japan Aerospace Exploration Agency (JAXA), a world-leader in SPS systems, now has a technology roadmap that proposes a 1 GW commercial system by 2030 [27].

Elsewhere, international conferences, workshops and committees of experts have been sprawling the SPS concept in recent times in order to promote international dialogue and coordinate SPS efforts. The on-going Power Symposium of the International Astronomical Congress (IAC), as well as periodic conferences dedicated to SPS and WPT have been reported, and also hosted on a dedicated online Space Solar Power Library [13], [29]. 
Another plus is the recent international assessment developed by the International Academy of Astronautics (IAA) Study [13], which has been serially referenced in this paper. Its key findings were: 1) need for new energy technologies such as SPS; 2) SPS is feasible; 3 ) SPS will soon be economically viable; 4) more research is needed to fine-tune all parts of the technology; 5) low-cost ETO transportation will make SPS commercially viable; 6) prototype testing-of-concept need to be initiated to boost technology confidence; 7) technological development is currently transient; 8) existing power networks for transmission; and, 9) need for regulatory and policy frameworks.

\section{CONCLUSION}

So far, SPS technology - not new at all - appears to be receiving wider attention from governments and key stakeholders. To this end, the satellite-based technology is gradually converging most of its trajectories for the development and production of a prototype. Besides, the impetus for SPS appears to be an underlying drive to address concurrent global challenges of energy demand for a growing world population, in the midst of increasing environmental pollution and certain oil depletion. Though bearing in mind the present huge cost of production and other critical factors, SPS technology invariably offers great promise to tap directly into the Sun's abundant solar energy for zero-carbon cum sustainable electricity production, and at a significantly greater efficiency than the current earth-based PV systems. The challenge however is that much work still needs to be done in terms of plugging together the technical and economic holes of the SPS technology, apparently making it a future source of power generation.

\section{ACKNOWLEDGMENT}

Authors Muncho J. Mbunwe \& Udochukwu B. Akuru from University of Nigeria, Nsukka, Nigeria and M. Ayaz Ahmad from University of Tabuk, Saudi Arabia have been working since a long time in personal joint collaboration. We would like to acknowledge the keen support in financial assistance for this research work to their respective Institutes / Universities [30-32].

Conflicts of Interest: The author(s) declare that there are no conflicts of interest regarding the publication of this paper. 


\section{References}

[1] Glaser, P. E. Power from the Sun: Its future. Science, 162 (3856) (1968), 857-861.

[2] Glaser, P. E. The Earth Benefits of Solar Power Satellites, The Space Congress Proceeding, 3, (1979), 5-11-5-25.

[3] Glaser, P. E., Maynard, O. E., Mackovciak, J., and Ralph, E. L, Arthur D. Little, Inc., Feasibility study of a satellite solar power station, NASA CR-2357, NTIS N74-17784, February 1974.

[4] Rich, Japan's solar revolution - the sky's (not) the limit. Tofugu.com: Posted May 29, 2014.

[5] Bullis, K., Startup to beam power from space, in MIT Technology Review: Potential Energy. K. Bullis (Ed.), 2009.

[6] Mankins, J. C., SPS-ALPHA: The first practical solar power satellite via arbitrarily large phased array (A 2011-2012 NASA NIAC Phase 1 Project), NASA Innovative Advanced Concepts Program, NiAC Phase 1 Final Report, 15 September 2012.

[7] Weitemeyer S, Kleinhans D, Vogt T, and Agert C, Integration of Renewable Energy Sources in Future Power Systems: The Role of Storage, Renewable Energy, 75(2015), 14-20.

[8] Fetter, S., Space Solar power: an idea whose time will never come? Phys. Soc. 33(1)(2004), 10-11.

[9] Murphy, T., Space-Based Solar Power. Available from: http://physics. ucsd.edu/do-themath/2012/03/space-based-solar-power/, 2012.

[10] Akuru, U.B. and Okoro, O.I. A prediction on Nigeria's oil depletion based on Hubbert's Model and the need for renewable energy, ISRN Renewable Energy, 2011(2011), Article ID 285649.

[11] REN21, Renewables 2010 global status report (Paris: REN21 Secretariat), 2010, Available online: https://www.ren21.net/reports/global-status-report/.

[12] Akuru, U.B., Okoro, O.I. and Chikuni, E., Impact of Renewable Energy Deployment on Climate Change in Nigeria, Journal of Energy in Southern Africa, (26)3, (2015), 125-134.

[13] Mankins, J. C. and Kaya, N. (Eds.), Space Solar Power, The first international Assessment of Space Solar Power: opportunities, issues and potential pathways forward. Internatinal Academy of Astronautics (IAA), August 2011.

[14] International Energy Outlook 2019. Available online at: https://www.eia.gov/outlooks/ieo/.

[15] Markad C, Markad S, and Mukhedkar M, Wireles Power Transmission by Using Solar Power Satellite, Int. J. Adv. Res. Electron. Commun. Eng. 3(12)(2014), 1793-1796.

[16] Ji, G., Xinbin, H. and Li, W. Solar power satellite research in China, Online Journal of Space Communication, Issue No. 16: China SPS Strategy and Schedule, Winter 2010.

[17] Ciotola, M. (Ed.), Space-Based Solar Energy: A brief review and analysis, National Solar Power Research Institute, 1998.

[18] Mankins, J. C. Energy from orbit: Solar Based Solar Power, AD ASTRA, National Space Society, Spring 2008. 
[19] Rouge, J. D. Space based solar power as an opportunity for strategic security, Phase 0 Architechture Feasibility Study, National Sceurity Space Office Interim Assessment, 10 October, 2007.

[20] Aleklett, K., Jakobsson, M. H. K., Lardelli, M., Snowden, S. and Soderbergh, B. The peak of the oil age - analysisng the world oil production. Energy Policy, 38(3)(2010), 1398-1414.

[21] Fan, W., Martin, H., Wu, J. and Mok, B. Space Based Solar Power, http:/ / docshare04.docshare.tips/files/10246/102466914.pdf.

[22] Nansen, R. H. Wireless power transmission: the key to solar power satelittes, IEEE Aerospace and Electronic Systems Magazine, 11(1)(1996), 33 - 39.

[23] Mcspadden J. O. and Mankins J. C, Space Solar Power programs and Microwave Wireless power transmission technology, IEEE Microwave Magazine, 3(4)(2002), 46-57.

[24] Gibbons, J. H., Solar power satellites, U.S. government Printing Office, Washington, August 1981.

[25] Jaffe, P., Hodkin, J., Harrington, F., Person, C., Nurnberger, M., Nguyen, B., LaCava, S., Scheiman, D., Stewart, G., Han, A., Hettwer, E., and Rhoades D. Sandwich module prototype progress for space solar power, Acta Astronautica, 94(2)(2014), 662-671.

[26] Pozar D. M, Microwave Engineering, Wiley, $4^{\text {th }}$ edition 2012.

[27] Sasaki, S., How Japan plan to build an orbital solar farm, IEEE Spectrum, 24(2014), 46-51.

[28] Mohammed S.S. and Ramasamy K. Solar PowerGeneration using SPS and Wireless Power Transmission. Proc. Int. Conf. Energy Environ. 2009, 413-418.

[29] https://space.nss.org/space-solar-power-library/ (last accessed 12.12.2019).

[30] C. Victoria Anghel Drugarin, Vyacheslav V. Lyashenko, Muncho J. Mbunwe, M. Ayaz Ahmad, Pre-processing of Images as a Source of Additional Information for Image of the Natural Polymer Composites, J. Analele Universitatii "Eftimie Murgu" Resita. Fascicula de Inginerie, 25(2) (2018), 11-16.

[31] M. Ayaz Ahmad, Mir Hashim Rasool, Jalal H. Baker, Shafiq Ahmad, Muncho J. Mbunwe, Nuclear Effect in terms of Hurst Exponent in ${ }^{28} \mathrm{Si}$-Emulsion Collisions at $14.6 \mathrm{~A} \mathrm{GeV}$, Proc. DAE Symp. Nuclear Phys. 63(2018), 956-957.

[32] Nursabah Sarikavakli, Syed Khalid Mustafa, M. Ayaz Ahmad, Vyacheslav Lyashenko, Muncho J. Mbunwe, An Interesting Approach of Bray-Liebhafsky (B-L) Oscillatory Chemical Reactions, Eur. J. Chem. Environ. Eng. Sci. 2(3) (2018), art01. 